\title{
Optimalisasi Perawatan Sistem Pendingin Mesin Utama Di Kapal MV. Nusantara Pelangi 101
}

\author{
Andriyan Adi Pratama ${ }^{1}$, Ningrum Astriawati ${ }^{2 *}$, Paulus Suhardi Waluyo ${ }^{3}$, Ruwinta \\ Wahyudiyana $^{4}$ \\ ${ }^{1}$ Alumni Prodi Permesinan Kapal, Sekolah Tinggi Maritim Yogyakarta, Jl. Magelang KM \\ 4.4, Yogyakarta 55284, Indonesia \\ ${ }^{2,3,4}$ Sekolah Tinggi Maritim Yogyakarta, Jl. Magelang KM 4.4, Yogyakarta 55284, \\ Indonesia \\ * Corresponding Author. E-mail : astriamath@gmail.com. Telp : 08995769219
}

\begin{abstract}
Abstrak
Kinerja mesin penggerak utama pada kapal dapat mengalami over heating atau panas yang berlebih. Untuk itu diperlukan sistem pendingin untuk menormalkan suhunya kembali. Over heating dapat membahayakan mesin penggerak utama, oleh sebab itu dibutuhkan kemampuan perawatan sistem pendingin yang benar. Penelitian ini bertujuan untuk mengetahui cara bagaimana perawatan sistem pendinginan pada Mesin penggerak utama tipe G8300ZC30B sebagai penggerak utama di Kapal MV. Nusantara Pelangi 101 milik perusahaan PT. Jatim Perkasa Lines. Pengumpulan data diperoleh dari observasi, wawancara dan dokumentasi. Analisis data pada penelitian ini dengan analisa deskriptif. Hasil dari penelitian ini adalah perawatan sistem pendingin mesin utama MV. Nusantara Pelangi 101 sudah berjalan optimal dengan rerata setelah dilakukan optimalisasi perawatan sebesar 89.67\%, sistem pendingin menggunakan sistem pendingin tertutup, bagian-bagian yang dirawat meliputi sea chest, pipa, saringan atau filter air laut, S.W Pump, FW Pump, F.W Cooler, Expansion Tank, dan kran yang sudah sesuai dengan prosedur.
\end{abstract}

Kata Kunci: Perawatan, Sistem Pendingin, Mesin Penggerak Utama

\begin{abstract}
The main propulsion engine on every ship is always experiencing overheating or excessive heat. For this reason, a cooling system is needed to normalize the temperature again. Over heating can harm the prime mover engine, therefore proper cooling system maintenance skills are required. This study aims to find out how to maintain the cooling system on the G8300ZC30B type prime mover engine as the main mover on the MV Ship. Nusantara Pelangi 101 belongs to the company PT. East Java Mighty Lines. Data collection was obtained from observation, interviews and documentation. Data analysis in this study with descriptive analysis. The result of this research is the maintenance of the main engine cooling system MV. Nusantara Pelangi 101 has been running optimally with an average after optimization of maintenance of $89.67 \%$, the cooling system uses a closed cooling system, the parts being treated include sea chests, pipes, filters or seawater filters, SW Pump, FW Pump, FW Cooler, Expansion Tank, and faucets that are in accordance with the procedure.
\end{abstract}


Keywords: Maintenance, Cooling Systems, Diesel Engines

\section{PENDAHULUAN}

Mesin penggerak utama yang harus bekerja terus-menerus saat dioperasikan, untuk mendukung kerja mesin tersebut harus ditunjang oleh beberapa bagian yang penting (Martyr \& Plint, 2011). Menurut Daryanto dalam (Purjiyono et al., 2019) Bagian-bagian penting tersebut terkait dengan suatu sistem, antara lain sistem pelumasan dan sistem pedinginan yang berfungsi untuk menghilangkan panas dari mesin. Mesin penggerak utama merupakan sebuah mesin konversi energi yang mengubah energi thermal hasil reaksi kimia antara bahan bakar dan udara menjadi energi mekanik (Kreith, 2000). Proses pembakaran bahan bakarnya terjadi akibat adanya tekanan udara yang tinggi di dalam ruang bakar sehingga disebut Compression Ignition Engine (Serrano et al., 2021). Selanjutnya, bahan bakar diinjeksikan/ dikabutkan ke ruang pembakaran untuk menghasilkan tenaga mekanik sebagai penggerak poros engkol (crankshaft). Mesin penggerak utama yang bekerja secara terus menerus ini akan mengakibatkan suhu yang tinggi baik di ruang silinder maupun diluarnya sehingga membutuhkan sistem pendingin untuk menjaga over heating(Van Maanen, 1986).

Menurut Kreith (2000) over heating pada mesin diesel dapat berakibat keausan dan kerusakan pada komponen-komponen mesin tersebut. Over heating terjadi akibat dari perpindahan panas yang terjadi pada dinding penukar kalor merupakan kombinasi perpindahan secara konveksi dan konduksi(Tambunan et al., 2019). Bagian-bagian tersebut salah satunya adalah sistem pendingin yang digunakan untuk mendinginkan komponen-komponen mesin yang terlalu panas atau menjaga temperatur mesin tetap normal. Pengoperasian mesin penggerak utama tanpa didukung dengan sistem pemeliharaan pendinginan yang baik yang digunakan untuk menjaga atau mencegah terjadinya panas yang berlebihan (over heating). Salah satu penyebab terjadinya kerusakan pada sistem pendingin adalah kurangnya perawatan pada sistem pendingin yang tidak sesuai(Yuliyanti et al., 2019). Supaya mesin penggerak utama dapat berfungsi secara optimal maka sistem pendingin harus berjalan dengan baik sehingga mesin dapat digunakan dalam jangka waktu yang lama, namun kenyataanya masih ada mesin yang digunakan tidak sesuai dengan target waktu yang telah ada dikarenakan kurangnya perawatan. Apabila sistem pendingin pada mesin penggerak utama selalu dilakukan perawatan sehingga dapat berjalan dengan baik, maka akan bisa mempengaruhi masa kinerja komponen mesin tersebut menjadi lebih tahan lama, dapat menekan biaya operasional, mengantisipasi kerusakan yang lebih parah dan untuk mengantisipasi kerusakan pada saat mesin sedang bekerja(Astriawati \& Wibowo, 2020).

Perawatan pada sistem pendingin pada mesin penggerak utama bertujuan untuk agar mesin berjalan dengan baik, hal ini dapat berjalan baik apabila optimalisasi perawatan dilakukan sesuai manual book dan prosedur yang telah 
ditetapkan(Wibowo \& Astriawati, 2021). Perawatan sebagai sebuah rutinitas yang harus dilakukan. Pada saat dilakukan observasi di lapangan pada mesin penggerak utama tipe G8300ZC30B di Kapal MV. Nusantara Pelangi 101 milik perusahaan PT. Jatim Perkasa Lines ada 27.5\% yang tidak dilakukan sesuai dengan prosedur dan manual book. Hal ini ada indikasi beberapa sistem tidak dapat bekerja secara optimal sehingga diperlukan tindakan perawatan yang lebih intensif. Tujuan penelitian ini untuk mengoptimalkan perawatan sistem pendingin tertutup pada mesin penggerak utama tipe G8300ZC30B di Kapal MV. Nusantara Pelangi 101 milik perusahaan PT. Jatim Perkasa Lines.

\section{METODE PENELITIAN}

Penelitian ini merupakan jenis penelitan deskriptif kualitatif. Penelitian ini dilakukan di kamar mesin Kapal MV. Nusantara Pelangi 101 milik perusahaan PT. Jatim Perkasa Lines. Data kapal MV. Nusantara Pelangi 101 sebagai berikut:

\begin{tabular}{|c|c|}
\hline Name Of Vessel & : MV. NUSANTARA PELANGI \\
\hline Call Sign & : J Z R M \\
\hline Owner & : PT. JATIM PERKASA \\
\hline Kind Of Vessel & : CONTAINER \\
\hline Imo Number & : 8666161 \\
\hline Mmsi Number & : 525200885 \\
\hline Official Number & : 2014 Ba NO. 3829/L \\
\hline Nationality & : INDONESIA \\
\hline Port Of Registry & : TANJUNG PRIOK \\
\hline Classification & : BKI \\
\hline Builder / Year & : 2007 \\
\hline Gross Tonnage & : $3106 \mathrm{~T}$ \\
\hline Netto Tonnage & $: 1814 \mathrm{~T}$ \\
\hline Dead Wigh Tonnage & $: 4980 \mathrm{~T}$ \\
\hline Loa & $: 96.5 \mathrm{M}$ \\
\hline$L b p$ & $: 90.8 \mathrm{M}$ \\
\hline Breadth Moulded & : $15.8 \mathrm{M}$ \\
\hline Depth Moulded & : 7.4 MA \\
\hline Capacity Of Container & : 280 TEUS \\
\hline In Hold & : 130 TEUS \\
\hline On Deck & : 120 TEUS \\
\hline Water Ballast & $: 900 \mathrm{~T}$ \\
\hline Fresh Water Tank Capacity & $: 60 \mathrm{~T}$ \\
\hline Light Ship Weight & : 2950.788 T \\
\hline Total B W & $: 1300 \mathrm{~T}$ \\
\hline Total Fo + Do & $: 120 \mathrm{~T}$ \\
\hline Main Engine ( $\mathrm{Kw}$ ) & : NINGBO / 1765 KW \\
\hline Auxilary Engine & : 6135AZCat / $138 \mathrm{KW}$ \\
\hline Speed & : 12 KNOTS \\
\hline
\end{tabular}


Cara pengumpulan data dilakukan dengan: (1) Metode observasi yaitu penelitian ini dilakukan dengan cara peninjauan langsung di lapangan tempat objek yang diteliti (Hasanah, 2017). Data dan informasi dikumpulkan melalui pengamatan secara langsung mengenai perawatan sistem pendingin di Kapal MV. Nusantara Pelangi 101 milik perusahaan PT. Jatim Perkasa Lines. (2) Metode wawancara yaitu suatu metode pengumpulan data yang diperlukan dengan cara bertanya langsung kepada orang yang menguasai bidang sekaligus bertatap muka secara langsung (Hasanah, 2017). Pada metode ini peneliti mengadakan wawancara dengan sebagian crew yang ada di kapal, seperti Kepala Kamar Mesin, Oiler dan Engineer (3) Metode dokumentasi adalah metode dengan melihat atau menganalisis dokumen-dokumen yang dibuat oleh subjek sendiri atau oleh orang lain dengan tujuan untuk mendapatkan gambaran dari sudut pandang subjek melalui suatu media tertulis dan dokumen lainnya yang ditulis atau dibuat langsung oleh subjek yang bersangkutan(Nilamsari, 2014). Pada metode ini peneliti menggunakan foto-foto bukti penelitian di Kapal MV. Nusantara Pelangi 101 milik perusahaan PT. Jatim Perkasa Lines. Analisis data pada penelitian ini dengan analisa deskriptif. Menurut Sujana dalam (Soendari, 2012) penelitian deskriptif adalah penelitian yang berusaha mendeskripsikan suatu gejala, peristiwa, kejadian yang terjadi pada saat sekarang. Data yang diperlukan dalam penelitian ini secara garis besar terdiri dari dua jenis data, yaitu:data primer meliputi observasi (pengamatan langsung) dan wawancara. Dalam peneltian ini peneliti menggunakan wawancara yang tidak terstruktur. Data yang diperoleh dalam penelitian ini adalah menggunakan data kapal dan data mesin kapal, data perawatan kapal, Jurnal kamar mesin dan unsur unsur yang relevan.

\section{HASIL DAN PEMBAHASAN}

Mesin penggerak utama pada kapal dirancang untuk dapat bekerja dalam waktu yang lama bisa berjam-jam/ berhari-hari secara efektif dan efisien. Hilangnya energi paling sering dan maksimum dari mesin adalah dalam bentuk energi panas. Untuk menghilangkan energi panas yang berlebihan harus menggunakan media pendingin (cooler) untuk menghindari gangguan fungsional mesin atau kerusakan pada mesin. Untuk itu, sistem pendingin dipasang pada kapal. Jenis sistem pendingin pada kapal MV.Nusantara Pelangi 101 adalah sistem pendingin tertutup. Sistem pendingin tertutup yang artinya ada media fluida/ air tawar yang mengalir di water jacket. Hal ini sejalan dengan hasil penelitian Maleev (1986) bahwa sistem pendinginan air sebagai bahan pendingin adalah air karena sistem pendingin air pendinginannya cukup baik dan tidak menimbulkan suara. Berikut skema sistem pendingin tertutup di Kapal MV. Nusantara Pelangi 101. 


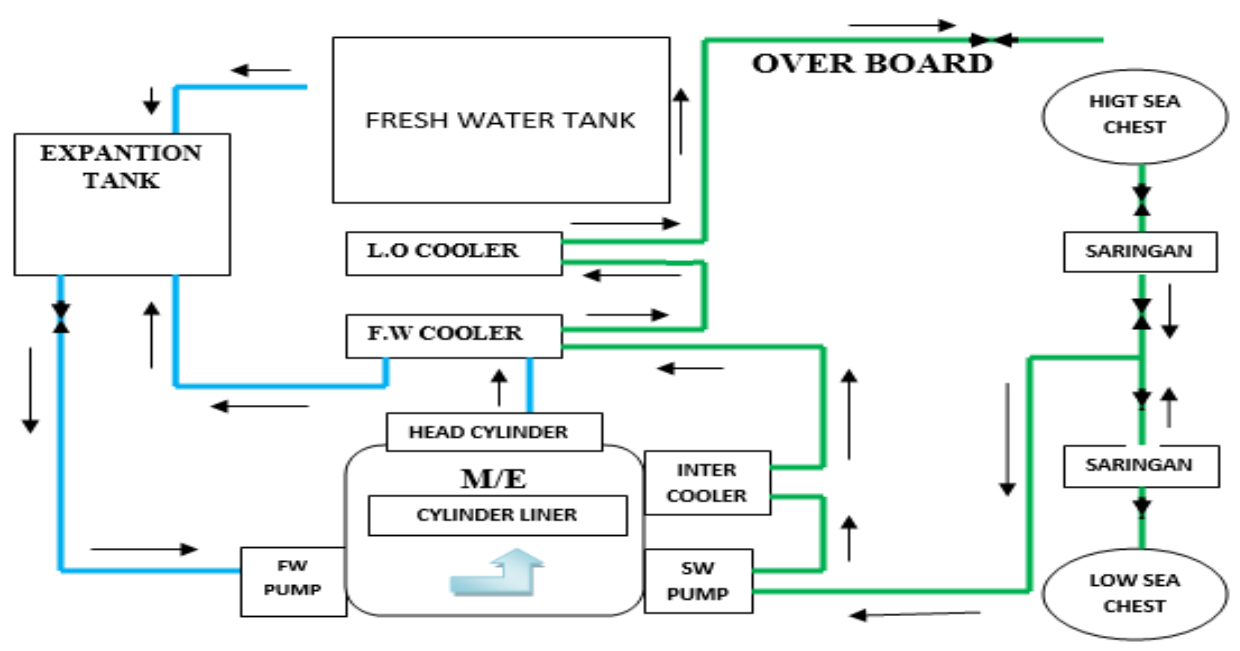

Gambar 1. Sketsa Sistem Pendingin Tertutup

\section{Perawatan Sistem Pendingin Air Tawar Pada Mesin Utama}

Expantion Tank merupakan media penampungan cairan berupa air tawar yang di gunakan untuk men-suplay kebutuhan air tawar dalam kamar mesin untuk pendingin mesin maupun kebutuhan lainnya. Proses sirkulasi/aliran sistem pendingin air tawar pada mesin penggerak utama meliputi : Expation Tank, fresh water cooling pump, sedangkan proses aliran sistem pendingin air laut pada cooler air tawar meliputi : sea chast, filter/saringan, cooling pump,lub oil cooler, FW cooler, dan keluar melalui over board. Perawatan Expasion tank yang di lakukan pada kapal MV. Nusantara Pelangi 101 tidak di lakukan secara berkala, hanya memperhatikan kurangnya air dalam tangki dan suhunya saja bahkan saat docking. Permasalahan yang sering terjadi antara lain: expansion tank tidak mengalirkan air, suhu air dalam expansion tank meningkat, kurangnya air di dalam tangki. Cara perawatannya antara lain: memeriksa air di dalam expansion tank tiap pergantian jam jaga, jika air dalam tangki kurang segera tambahkan dengan air tawar, mengalirkan air dalam expansion tank ke dalam tangki air tawar sebagian dan mengisi kembali expansion tank dengan air tawar, memeriksa pipa-pipa yang menuju ke tiap cylinder apakah ada yang tersumbat.

Pompa air tawar (Centrifugal) merupakan alat pemindah zat cair dari suatu tempat ke tempat yang lain. Cara kerjanya menggunakan energi rotasi yang berasal dari mesin atau motor listrik sebagai pemutar pompa, dengan putaran pompa cairan dapat memasuki impeller dan mengalir keluar. Perawatan pada centrifugal pump jika tidak bisa menghisap adalah dengan melihat manometer hisap, penyebab antara lain: Motor penggerak tidak normal, terdapat kebocoran dari packing pompa, tersumbatnya aliran pompa sehingga pompa vacum air tidak menerima suplay air, tersumbatnya saringan pompa sehingga pompa air tidak dapat menghisap air dalam ruangan pompa. Jika air dalam saluran hisap dapat di hisap tetap menghasilkan sedikit air penyebab antara lain :Pipa tersumbat atau saringan tersumbat, kipas atau 
impeller sebagian atau keseluruhan tersumbat. Cara perawatannya antara lain sebagai berikut : memberikan pelumas pada bearing, membersihkan saringan hisap secara berkala, membersihkan impeller secara berkala, menggantikan rames packing apabila ada kebocoran. Berikut jenis pompa air tawar pada Kapal MV. Nusantara Pelangi 101.

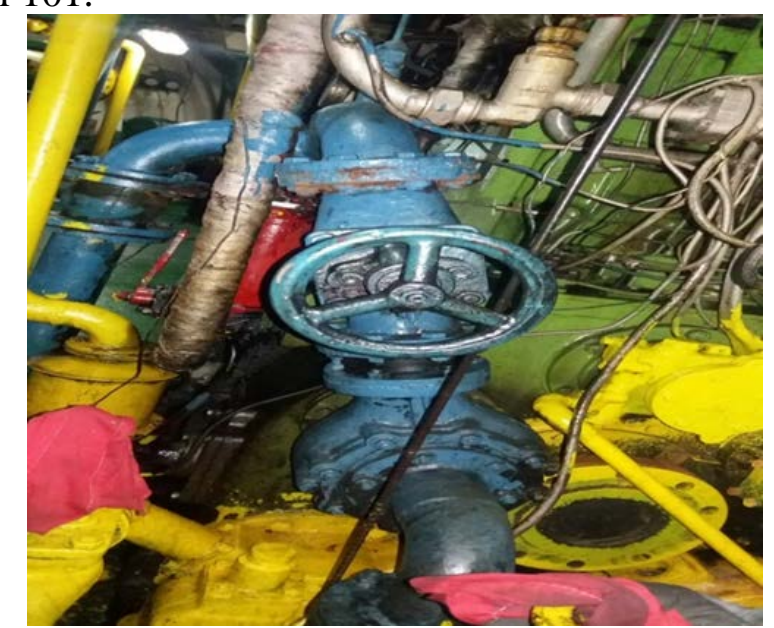

Gambar 2. Pompa Air Tawar Kapal MV. Nusantara Pelangi 101

Fresh water cooler merupakan tempat pendingin air tawar dengan air laut., sedangkan lub oil cooler merupakan tempat pendingin oli dengan air laut. Air laut sebagai media pendingin yang mengalir ke dalam cooler, air tawar dan oli melewati pipa-pipa kecil yang terlewat air laut sehingga suhu air tawar dalam cooler dapat di dinginkan oleh air laut tersebut. Agar cooler dapat dipakai dalam jangka waktu yang lama, maka perlu mendapat pemeliharaan yang baik dan teratur ataupun berkala. Pemeliharaan sistem pendingin ini di lakukan untuk mencegah kerusakankerusakan secara dini sebelum melampaui batas pemakaiannya. Perawatan cooler yang baik dan teratur merupakan suatu usaha penghematan serta menjaga agar komponen-komponen lainnya tetap dapat dipakai serta stabil dalam kerjanya. Halhal yang perlu di perhatikan dalam pemeliharaan cooler adalah membersihkan bagian luar cooler, dapat di lakukan dengan menggunakan kain majun atau lap agar bila terjadi kebocoran dapat terlihat dari tetesan atau resapan air keluar dari cooler, memeriksa bila terjadi kebocoran di air pendingin melalui pipa-pipa cooler dengan melihat adakah tetesan dari pipa atau di raba bagian flange, jika ingin membersihkan bagian dalam cooler pastikan Sea water pump dalam keadaan mati dan menutup dahulu pipa-pipa yang masuk dan keluar dari cooler, lepas pipa-pipa pada cooler baik bagian air masuk dan keluar cooler, buka tutup cooler dengan melepas baut satu-persatu hingga semua baut terlepas, tunggu sampai semua sisa air keluar baru membersihkan rongga-rongga yang di aliri air laut dengan rotan yang panjang sampai semua kotoran dalam rongga-rongga bersih.

Setelah semua bagian dalam cooler di bersihkan mengganti packing yang baru agar lebih terjamin kerapatannya, kemudian memasang kembali tutup cooler 
dan mengencangkan bautnya sampai benar-benar rapat dan memasang kembali pipa-pipa yang sudah di lepas tadi agar cooler bisa segera di cek kembali. Buka kembali kran-kran yg sudah di tutup tadi dan nyalakan pompa air laut agar bisa di cek kebocorannya dan agar cooler bisa digunakan kembali sesuai fungsinya kemudian membersihkan cooler dengan majun atau lap supaya di ketahui letak kebocoran bila masih terdapat kebocoran. Bila tidak ditemui kebocoran maka fresh water cooler siap di operasikan kembali.

\section{Perawatan Sistem Pendingin Air Laut Pada Cooler Air Tawar}

Sea chest merupakan lubang yang terdapat pada lambung kapal yang di gunakan untuk menghisap air laut ke dalam kapal, yang di gunakan sebagai pendingin mesin, ballast, air deck, dan untuk kebutuhan lainnya. Untuk daerah pelayaran yang dangkal disarankan untuk menggunakan sisi pengisian air laut yang lebih tinggi (hight sea chest), sedangkan untuk perairan yang dalam disarankan menggunakan sisi pengisian air laut yang rendah (low sea chest). Perawatan sea chest di kapal MV. Nusantara Pelangi 101 biasanya pada saat docking. Masalah yang sering terjadi pada sea chest antara lain : Adanya kerang-kerang yang menempel, adanya kotaran seperti plastik, kayu dan yang lainnya, terjadinya korosi pada sea chest. Adapun perawatannya pada saat docking di galangan misalkan: dengan disemprot dengan water jet, melakukan penyekrapan, pengecekan pelat pada sea chest dengan tes kerosin, penggantian zinc anode, pengecatan pada bagian sea chest.

Saringan/filter merupakan yang di gunakan untuk memisahkan bagian yang tidak di gunakan (zat cair ke padat) biasanya saringan air laut terdapat sampahsampah dari laut, ikan-ikan dan lain sebagainya. Saringan air laut masuk adalah bagian yang cukup penting dalam sistem pendinginan karena berhubungan langsung dengan luar. Semua yang ada di laut dapat masuk ke dalam mesin utama oleh karena itu di pasang filter atau penyaringan. Plat penyaringan sering kali dapat masalah seperti tersumbat oleh kotoran atau sampah yang terhisap masuk, sehingga aliran air laut yang seharusnya mendinginkan cooler menjadi kurang efektif, maka sea chest perlu mendapat perhatian agar sistem pendingin kapal dapat bekerja dalam keadaan yang baik dan kegiatan pelayaran dapat berlangsung dengan lancar tanpa adanya masalah atau kendala. Tanda-tanda saringan yang mengalami kurang lancar atau tersumbat antara lain sebagai berikut: Cooler menjadi panas dari temperatur normal, manometer air laut berkurang tekanannya, aliran air laut over board yang keluar di luar lambung terlihat kecil, Terdengar alarm dan lampu alarm low presure sea water menyala.

Urutan perawatan membersihkan saringan adalah menutup kran masuk dan keluar dari sea chest, air laut yang ada pada rumah saringan di kuras untuk mengetahui apakah ada sampah yang terselip masuk, apabila ada di ambil dan dibersihkan, plat penyaring atau filter di ambil dan di cek, bila masih bagus di bersihkan dengan di semprot air dan di sikat dengan sikat kawat, bila sudah kurang bagus di ganti dengan yang baru, kemudian pasang kembali ke tempat semula, Packing dan deck sheet di pasang pada posisi yang sudah di tandai, memasang 
dengan semua baut tapi tidak di ikat, membuka kran air masuk di buka, membersihkan deck sheet dan mengolesi dengan greace atau gemuk dengan bautnya untuk mencegah terjadinya karat, membuka kran air laut over board, menyalakan pompa untuk running test, jika baik berjalan normal bersihkan alat dan tempat sekitar, bila sudah selesai kegiatan pembongkaran di catat pada buku harian

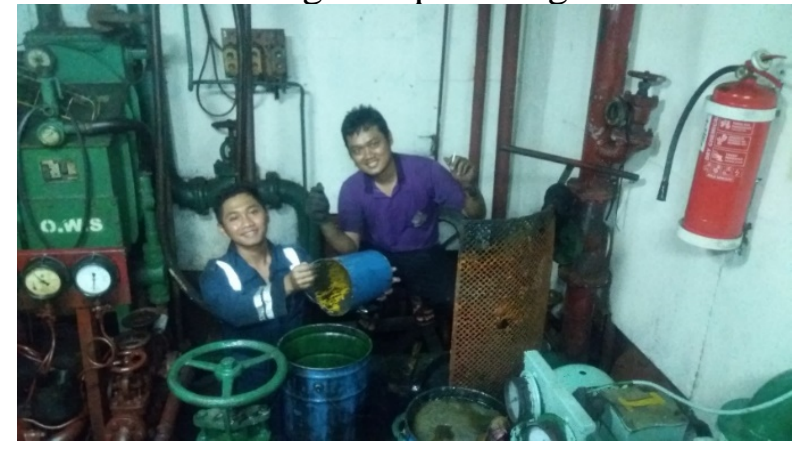

Gambar 3. Proses pembersihan Filter atau Saringan

Pompa air laut (Centrifugal) merupakan alat pemindah zat cair dari suatu tempat ke tempat lain. Cara kerjanya adalah menggunakan energi rotasi yang berasal dari mesin atau motor listrik untuk memutar pompa, dengan putaran pompa cairan memasuki impeller dan mengalir secara radial. Perawatan Sea Water Pump / Pompa Air Laut jika tidak bisa menghisap, yang dapat di periksa adalah dengan melihat manometer hisap, penyebab antara lain :motor penggerak tidak normal, terdapat kebocoran dari packing pompa, tersumbat pada aliran pompa sehingga pompa vacum air tidak menerima suplay air, tersumbat saringan pompa sehingga pompa air tidak dapat menghisap air dalam ruangan pompa. Jika air dalam saluran hisap dapat di hisap tetap menghasilkan sedikit air penyebab antara lain: Pipa tersumbat atau saringan tersumbat, kipas atau Impeller sebagian atau keseluruhan tersumbat. Cara perawatannya pompa air laut sebagai berikut: pemberian pelumas pada bearing, membersihkan saringan hisap secara berkala, membersihkan impeller secara berkala.

Over board merupakan lubang yang terdapat pada lambung kapal yang di gunakan sebagai keluarnya air laut dari dalam kapal. Air laut yang telah mendinginkan sejumlah komponen-komponen mesin atau air buangan dari dalam kapal yang melalui dari lubang tersebut. Perawatan pada system pendingin untuk mengoptimalkan kinerja pada bagian-bagian mesin yang diidinginkan meliputi: Cylinder Jacket, Cylinder Cover, dan Cylinder Liner.

\section{Efektifitas Optimalisasi Perawatan Sistem Pendingin}

Dari berbagai jenis perawatan yang terdapat di sistem pendingin tertutup pada Mesin penggerak utama tipe G8300ZC30B terdapat kenaikan sebelum dan setelah dilakukan perawatan secara intensif. Ada 6 komponen dari sistem pendingin yang menjadi perhatian pokok pada penelitian ini, di antaranya: Exspansion Tank, Fresh Water Pump, Fresh Water Cooler, Sea Chest, Saringan, Sea Water Cooler Perbandingan hasil observasi antara sebelum dan setelah dilakukan optimalisasi 
perawatan dengan pedoman manual book seperti yang ditunjukkan pada Gambar 4 berikut.

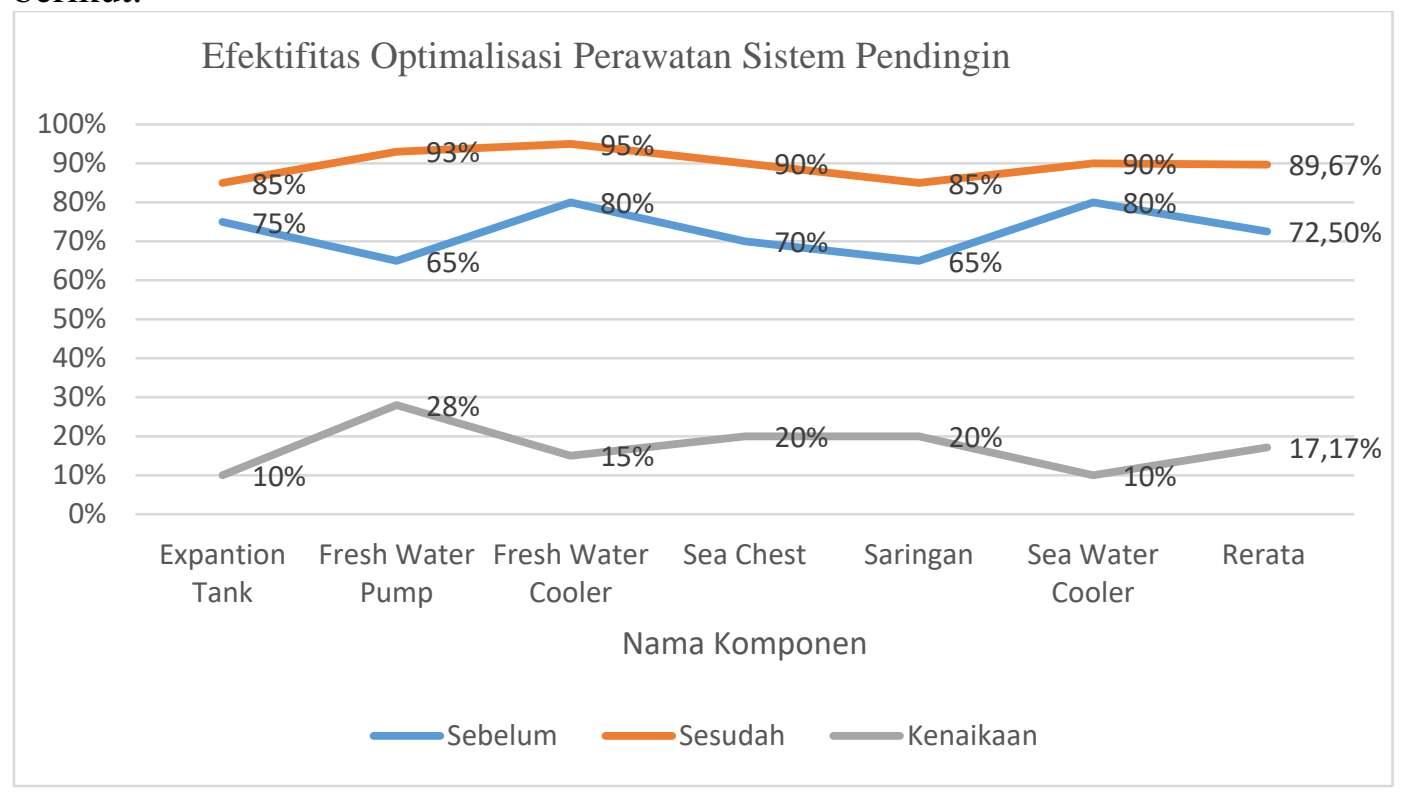

Gambar 4. Grafik Efektivitas Optimalisasi Perawatan Sistem Pendingin

Dari grafik di atas diperoleh bahwa terjadi peningkatan efektivitas implementasi manual book dalam perawatan semua komponen sistem pendingin. Pada komponen Exspansion Tank, efektivitas implementasi manual book sebelum optimalisasi berkisar $75 \%$ dan setelah dilakukan optimalisasi perawatan naik sebesar 10\%, sehingga efektivitas menjadi 85\%. Pada komponen Fresh Water Pump, efektivitas implementasi manual book sebelum optimalisasi hanya berkisar 65\% dan setelah dilakukan optimalisasi naik sebesar 28\% sehingga efektivitas menjadi 93\%. Pada komponen Fresh Water Cooler, mengalami kenaikan sebesar $15 \%$ dari yang sebelumnya $80 \%$ dan setelah dilakukan optimalisasi menjadi 95\%. Pada komponen Sea Chest, efektivitas implementasi manual book sebelum optimalisasi hanya berkisar $70 \%$ dan setelah dilakukan optimalisasi perawatan naik sebesar 20\% sehingga efektivitas menjadi $90 \%$.

Pada komponen Saringan, mengalami kenaikan efektivitas implementasi manual book sebesar 20\% dari yang sebelumnya kisaran 65\% dan setelah dilakukan optimalisasi menjadi 85\%. Pada komponen Sea Water Cooler, efektivitas implementasi manual book sebelum optimalisasi berkisar $80 \%$ dan setelah dilakukan optimalisasi perawatan naik sebesar $10 \%$, sehingga efektivitas menjadi 90\%. Secara keseluruhan rerata sebelum dilakukan optimalisasi perawatan efektivitas implementasi manual book pada sistem pendingin berkisar $72.50 \%$, dan rata-rata mengalami kenaikan sebesar $17.7 \%$ sehingga rerata setelah dilakukan optimalisasi perawatan dengan pedoman manual book menjadi $89.67 \%$. Berdasarkan rerata yang diperoleh, perawatan sistem pendingin tertutup pada 
Mesin penggerak utama tipe G8300ZC30B pada Kapal MV. Nusantara Pelangi dapat berjalan dengan optimal sehingga dapat mempertahankan kapal selalu dalam kondisi laik laut dalam segala cuaca dan tempat.

\section{SIMPULAN}

Sistem pendingin mesin utama MV. Nusantara Pelangi 101 menggunakan sistem tertutup yaitu air laut mendinginkan air tawar kemudian air tawar mendinginkan mesin utama. Bagian-bagian yang dirawat meliputi Sea chest, pipa, saringan atau filter air laut, pompa air laut dan tawar, F.W cooler, expansion tank, dan kran yang sudah sesuai dengan prosedur. Perawatan sistem pendingin yang ada di Kapal MV. Nusantara Pelangi 101 berjalan dengan baik dan sesuai dengan prosedur. Optimalisasi yang dilakukan mencapai $89.67 \%$ sesuai dengan implementasi manual book yang diterapkan pada komponen sistem pendingin mesin diesel

\section{DAFTAR PUSTAKA}

Astriawati, N., \& Wibowo, W. (2020). Perawatan Sistem Pendingin Mesin penggerak utama Pada Whell Loader Komatsu Wa120-3cs. Jurnal Teknovasi: Jurnal Teknik Dan Inovasi, 7(2), 76-85.

Hasanah, H. (2017). TEKNIK-TEKNIK OBSERVASI (Sebuah Alternatif Metode Pengumpulan Data Kualitatif Ilmu-ilmu Sosial). At-Taqaddum. https://doi.org/10.21580/at.v8i1.1163

Kreith, F, dan Prijono, A. (2000). Prinsip-prinsip Perpindahan Panas. Jakarta: Erlangga.

Kreith, A. (2000). F, dan Prijono,“. Prinsip-Prinsip Perpindahan Panas,” Jakarta: Erlangga.

Maleev, V. L. (1986). Operasi dan pemeliharaan mesin disel: konstruksi, operasi, pemeliharaan dan perbaikan mesin disel. Erlangga, Jakarta.

Martyr, A. J., \& Plint, M. A. (2011). Engine testing: theory and practice. Elsevier.

Nilamsari, N. (2014). Memahami studi dokumen dalam penelitian kualitatif. WACANA: Jurnal Ilmiah Ilmu Komunikasi, 13(2), 177-181.

Purjiyono, Astriawati, N., \& Santosa, P. S. (2019). Perawatan Sistem Pelumasan Mesin Utama Pada Kapal Km. Mutiara Sentosa II. Jurnal Teknovasi: Jurnal Teknik Dan Inovasi, 6(1), 74-80.

Serrano, J. R., Arnau, F. J., García-Cuevas, L. M., \& Farias, V. H. (2021). Oxy-fuel combustion feasibility of compression ignition engines using oxygen separation membranes for enabling carbon dioxide capture. Energy Conversion and Management, 247, 114732.

Soendari, T. (2012). Metode Penelitian Deskriptif. Bandung, UPI. Stuss, Magdalena \& Herdan, Agnieszka, 17. 
Tambunan, K., Fanani, Z., \& Prihajatno, M. (2019). Analisis Laju Perpindahan Panas Sistem Pendingin Air Tawar pada Engine Generator Listrik. Jurnal Airaha, 8(02), 37-44.

Van Maanen, P. (1986). Motor Diesel Kapal. Jakarta: Nautech.

Wibowo, W., \& Astriawati, N. (2021). Sistem Pendingin Tertutup Pada Mesin penggerak utama Tipe Diesel MAK 8M32 Sebagai Penggerak Utama Kapal Motor LIT ENTERPRISE. Jurnal POLIMESIN, 19(1), 28-34.

Yuliyanti, F., Budiyono, B., \& Prasetyo, I. (2019). Identifikasi Sistem Pendingin Pada Mesin penggerak utama Mitsubishi 100 Ps. Surya Teknika: Jurnal Ilmiah Teknik Mesin, 4(1), 19-24. 